\title{
МЕТАБОЛИЧЕСКИЙ СТАТУС ПАЦИЕНТОВ С ОЖИРЕНИЕМ И НАРУШЕНИЕМ УГЛЕВОДНОГО ОБМЕНА
}

Лапик И.А.

ФГБНУ «НИИ питания», Москва

ЦЕЛЬ: оценка метаболического статуса у пациентов с ожирением и нарушением углеводного обмена.

МАТЕРИАЛЫ И МЕТОДЫ: обследовано 60 пациентов с ожирением I-III степени и нарушением углеводного обмена (с нарушенной гликемией натощак, нарушенной толерантностью к глюкозе). ДНК пациентам выделяли из крови стандартным методом с использованием многокомпонентного лизирующего раствора, разрушающего комплекс ДНК с белком и последующей сорбцией на магнитные частицы, покрытые силикагелем, с использованием набора реагентов «РеалБест ДНК-экстракция 3», производства ЗАО «Вектор-Бест», Новосибирск, Россия. Генотипирование проводили с применением аллель-специфичной амплификации с детекцией результатов в режиме реального времени и использованием TaqManзондов, комплементарных полиморфным участкам ДНК.

Для исследования метаболического статуса использовали метод непрямой калориметрии.

РЕЗУЛЬТАТЫ: при изучении показателей метаболического статуса (скорости окисления жиров, белка и углеводов) у пациентов с ожирением и нарушением углеводного обмена (с нарушенной гликемией натощак, нарушенной толерантностью к глюкозе) при различных полиморфных вариантах гена FTO были выявлены достоверные изменения анализируемых параметров в исследуемых группах. У носителей генотипа T/T скорость окисления жиров составила $52 \pm 2 \%$, у носителей генотипа $A / T-21 \pm 3 \%$, генотипа

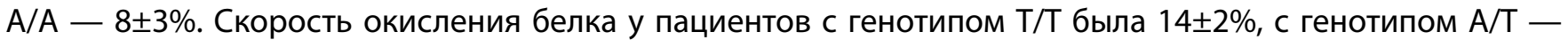
$15 \pm 3 \%$, с генотипом $A / A-17 \pm 3 \%$. Скорость окисления углеводов у носителей генотипа T/T составила $31 \pm 4 \%$, генотипа $A / T-74 \pm 5 \%$, генотипа $A / A-79 \pm 4 \%$. У пациентов с генотипами $A / T$ и A/A наблюдались метаболические нарушения в виде снижения скорости окисления жиров в среднем на $18 \%$. При этом у носителей мутантного аллеля А в гетерозиготном и гомозиготном варианте скорость окисления жиров была достоверно ниже, чем у носителей аллеля $\mathrm{T}, \mathrm{p}<0,05$. У пациентов с генотипом T/T наблюдались метаболические нарушения в виде снижения скорости окисления углеводов в среднем на $25 \%$. Скорость окисления углеводов у пациентов с генотипом T/Т была достоверно ниже, чем у пациентов с генотипами $\mathrm{A} / \mathrm{T}$ и $\mathrm{A} / \mathrm{A}, \mathrm{p}<0,05$.

ВЫВОдЫ: оценка метаболического статуса пациентам с ожирением и нарушением углеводного обмена позволит разработать персонализированные подходы к диетотерапии данных заболеваний.

Научно-исследовательская работа по подготовке рукописи проведена за счет средств субсидии на выполнение государственного задания. 